\title{
Further clinical observations on the pulmonary effects of paraquat ingestion
}

\author{
TIM HIGENBOTTAM, PETER CROME, CONSTANCE PARKINSON, AND JOHN NUNN
}

From Guy's Hospital, London SE1 9RT, UK

\begin{abstract}
Five patients are reported who developed evidence of acute lung damage after proved ingestion of paraquat. In two the lung changes resolved; in one an aspiration pneumonia occurred, which was successfully treated, while two developed fatal pulmonary oedema. These pulmonary complications after paraquat intoxication appear more common than the progressive pulmonary fibrosis previously described. It is suggested that acute pulmonary oedema is a response to large doses, usually of Gramoxone, that subclinical lung changes result from small doses, usually of Weedol, and that pulmonary fibrosis occurs after intermediate doses.

Preliminary data on plasma paraquat concentrations suggest that these are of value in prognosis.
\end{abstract}

Until a few years ago the most commonly encountered form of paraquat poisoning was that in which Gramoxone (a $20 \% \mathrm{w} / \mathrm{v}$ concentrate) was apparently accidentally ingested. Of these patients, several suffered transient renal and hepatic dysfunction, but progressive pulmonary fibrosis often caused death two to three weeks after ingestion. This led to the idea that paraquat ingestion associated with pulmonary complications was invariably fatal (Cooke et al, 1973).

More recent experience at the London Centre of the National Poisons Information Service is that this form of paraquat poisoning is now uncommon. Of the 188 cases of ingestion reported to the centre from 1974 to 1976,57 died acutely within seven days and only 12 died later with evidence of pulmonary fibrosis. The remaining 119 patients survived without ill effects and of these, 111 had swallowed the $2.5 \% \mathrm{w} / \mathrm{v}$ granular form of paraquat, Weedol. A clinical difference appeared to have developed between those taking small amounts who survived and those swallowing large amounts of paraquat, usually in the form of Gramoxone, who developed acutely fatal complications.

To exemplify this present and more diverse pattern of intoxication we have selected for reporting five patients who developed differing pulmonary complications after swallowing paraquat.

\section{Case reports}

During 1976-7 a total of six patients were admitted to Guy's Hospital after taking Gramoxone and a further three after Weedol ingestion. All the patients who took Gramoxone died, only one surviving for longer than seven days. On the other hand, all those swallowing Weedol survived. From these, five patients were selected to represent the different pulmonary complications that may be seen after paraquat intoxication. Initially, all were subjected to gastric aspiration and lavage, and then received oral Fuller's Earth $(20 \% \mathrm{w} / \mathrm{v})$ and magnesium sulphate $(5 \% \mathrm{w} / \mathrm{v})$ in doses of $250 \mathrm{ml}$ four-hourly for 48 hours. Intravenous fluids were given to produce a urine output of three litres over the first 24 hours. No additional oxygen was administered unless the $\mathrm{PaO}_{2}$ fell below $6 \mathrm{kPa}$, as in our two fatal cases 24 hours before death. In addition three patients (cases 3,4 , and 5) received charcoal haemoperfusion therapy (Vale et al, 1977). The urinary paraquat was detected colorimetrically (Widdop, 1976), and the plasma paraquat was estimated by radioimmunoassay (Levitt, 1977). Measurements of respiratory function were performed upon a Vitalograph and the gas transfer test machine (P K Morgan Ltd). These were compared with the predicted values for Europeans (Cotes, 1975).

\section{CASE 1}

A 27-year-old man swallowed two sachets of Weedol. The urine test for paraquat was moderately positive and the plasma paraquat, estimated three hours after ingestion, was $120 \mathrm{ng} / \mathrm{ml}$. Initially, there were no abnormal clinical findings, 
and his chest radiograph was clear. He remained asymptomatic over the subsequent five days, although the plasma creatinine concentration rose to $226 \mathrm{mmol} / 1$ and the aspartate aminotransferase (AST) to $46 \mathrm{u} /$ litre. Clinical examination then showed bilateral basal late inspiratory crackles, and his chest radiograph showed bilateral shadowing scattered through the upper and mid-zones (fig 1).

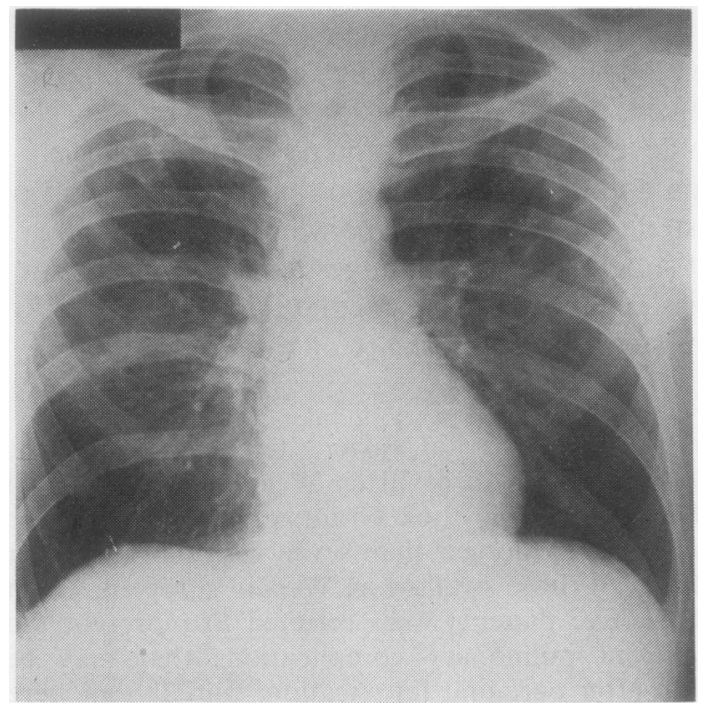

Fig 1 Chest radiograph of case 1 five days after paraquat ingestion showing peripheral bilateral shadowing of upper and mid-zones.

The forced expired volume in one second $\left(\mathrm{FEV}_{1}\right)$ and vital capacity (VC) had not altered during this time, which remained at $100 \%$ of the predicted values. However, the transfer factor for carbon monoxide fell (fig 2). Two weeks after admission his chest signs had receded, the gas transfer factor had begun to return to the predicted value, and his plasma creatinine concentration and AST were normal.

A follow-up one year later showed further improvement in respiratory function (fig 2) and a clear chest film.

\section{CASE 2}

Another 27-year-old man stated that he had swallowed $30-60 \mathrm{ml}$ of Gramoxone but vomited immediately afterwards. The urine test for paraquat was only weakly positive, and the initial plasma paraquat concentration eight hours after ingestion was $50 \mathrm{ng} / \mathrm{ml}$. He had oral and pharyngeal ulceration but no other abnormal physical signs. In-

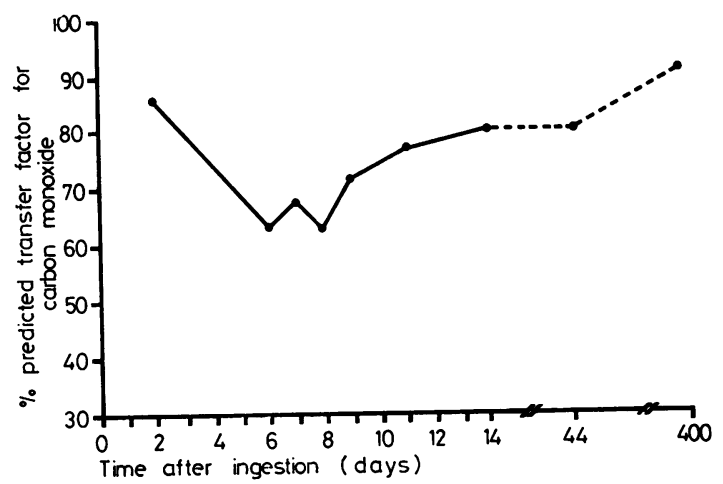

Fig 2 Change observed in gas transfer factor for carbon monoxide in case 1 after swallowing paraquat. Gas transfer factor is shown as percentage of predicted value.

itially, the AST rose to $60 \mathrm{u} / 1$, falling to within the normal range within two weeks. Throughout his admission his chest radiograph remained clear, and neither his FEV $_{1}$ nor VC fell. However, 11 and 13 days after ingestion the gas transfer factor for carbon monoxide was $64 \%$ of the predicted value, rising to $81 \%$ of the predicted level two months later. He remained well with no respiratory complications some two years after taking the paraquat.

\section{CASE 3}

A 47-year-old man drank the contents of a sachet of Weedol and was subjected to gastric lavage. The four hour plasma paraquat concentration was $115 \mathrm{ng} / \mathrm{ml}$. Initially he was asymptomatic and had minimal radiographic shadowing at the right base (fig 3). Two days after admission a fever and leucocytosis developed. The chest film now showed, predominantly, right lower lobe shadowing (fig 4). Aspiration pneumonia was diagnosed, and antibiotic treatment begun. Within the next five days he improved clinically and there was considerable clearing of the lungs on the chest $N$ film. From the time of admission to the resolution $\underset{\mathrm{W}}{\mathrm{N}}$ of chest signs the $\mathrm{FEV}_{1}$ and VC remained unchanged, and the gas transfer factor for carbon 0 monoxide, although initially $68 \%$, rose only to $\stackrel{\overparen{D}}{\overparen{D}}$ $72 \%$ of predicted. At no time during his admission $\stackrel{\oplus}{?}$ did either the AST or the blood urea rise.

\section{CASE 4}

A 56-year-old woman drank an undetermined amount of Gramoxone. Three hours later the initial plasma paraquat concentration was $940 \mathrm{ng} /$ $\mathrm{ml}$. Although showing oral and pharyngeal ulcer- 


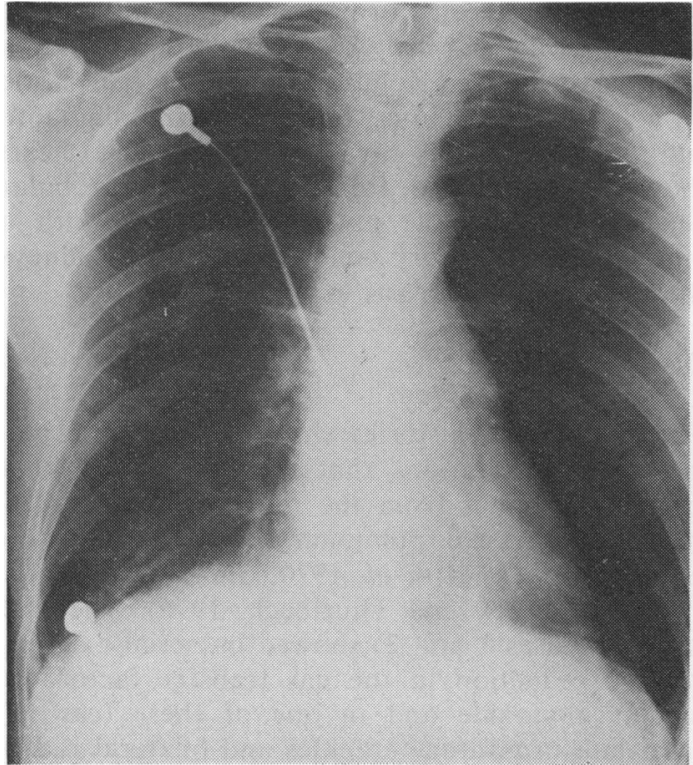

Fig 3 Admission chest radiograph of case 3.

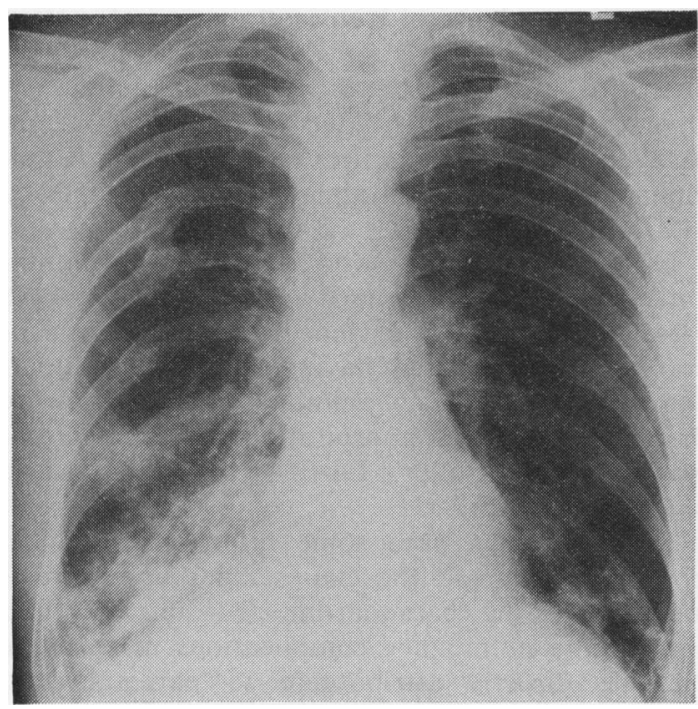

Fig 4 Chest radiograph of case 3 two days after swallowing paraquat showing basal shadowing predominantly in right lower zone.

ation, there were no abnormal physical signs on examination of her chest. Within four days she became severely dyspnoeic and had begun to produce copious quantities of clear sputum. The chest radiograph at this time showed bilateral shadowing (fig 5) and, although the dynamic lung volumes were greater than their predicted values, the gas transfer factor was only $35 \%$ of the predicted value. The plasma creatinine concentration was raised to $240 \mathrm{mmol} / 1$ and the AST was raised at $80 \mathrm{u} / 1$. Despite assisted ventilation her clinical condition progressively deteriorated, and she died in respiratory failure six days after taking paraquat.

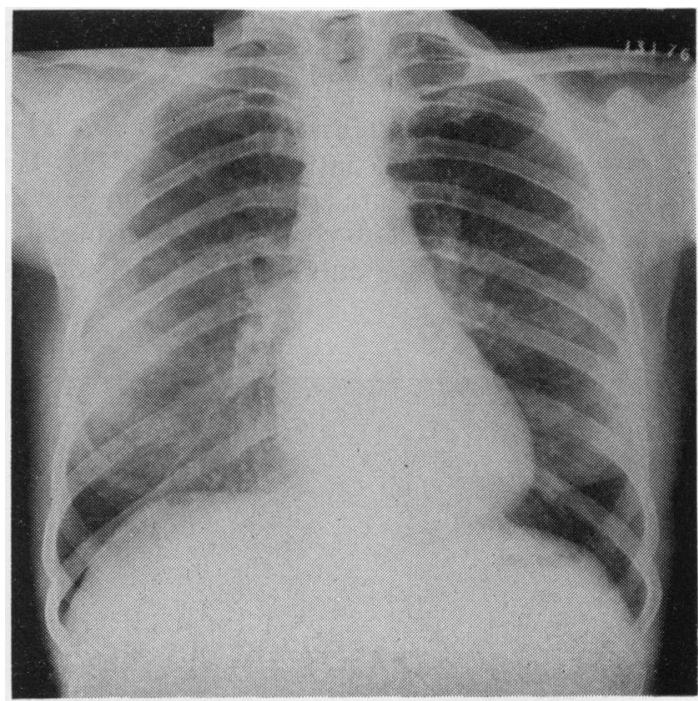

Fig 5 Chest radiograph four days after paraquat ingestion in case 4 showing widespread bilateral lung shadowing.

At necropsy the major pathological changes were confined to the lungs, liver, and kidneys. Copious clear mucus was present throughout the trachea and bronchi. The lungs were oedematous and congested; the right lung weighed $1025 \mathrm{~g}$ and the left lung $900 \mathrm{~g}$. In addition to these changes, light microscope examination showed widespread intra-alveolar haemorrhage and hyaline membrane formation within respiratory bronchioles and alveoli. Mononuclear cells with oval nuclei and prominent nucleoli were present in both alveolar walls and spaces. These cells resembled the "profibroblasts" described by Smith and Heath (1975) in the lungs of rats exposed to paraquat. Foci of bronchiolar epithelial cell proliferation were present extending into adjacent alveoli. The liver showed necrosis of centrilobular cells associated with a mixed polymorphonuclear and mononuclear cell infiltrate. Renal tubular necrosis was present, as defined by cellular and hyaline casts and tubular epithelial regeneration. 


\section{CASE 5}

A 28-year-old man swallowed an eggcupful of Gramoxone. Four hours later the plasma paraquat concentration was $420 \mathrm{ng} / \mathrm{ml}$. Initial examination showed oral and pharyngeal ulceration, and he complained of breathlessness. Over the next three days he became progressively more breathless and began to produce large quantities of clear frothy sputum. The chest radiograph at this stage showed bilateral diffuse shadowing (fig 6). He was unable, due to severe breathlessness, to perform the carbon monoxide gas transfer test. The $\mathrm{FEV}_{1}$ was $20 \%$ of the predicted value, and the VC was only $30 \%$. The arterial gas tension was $\mathrm{PaO}_{2} 9 \cdot 7 \mathrm{kPa}$ $(73 \mathrm{mmHg})$ and $\mathrm{PaCO}_{2} 5.0 \mathrm{kPa}(38 \mathrm{mmHg})$. He died of respiratory failure seven days after taking paraquat despite assisted ventilation. Terminally, his blood urea had risen only to $13 \mathrm{mmol} / \mathrm{l}$ and his AST to $80 \mathrm{u} / 1$.

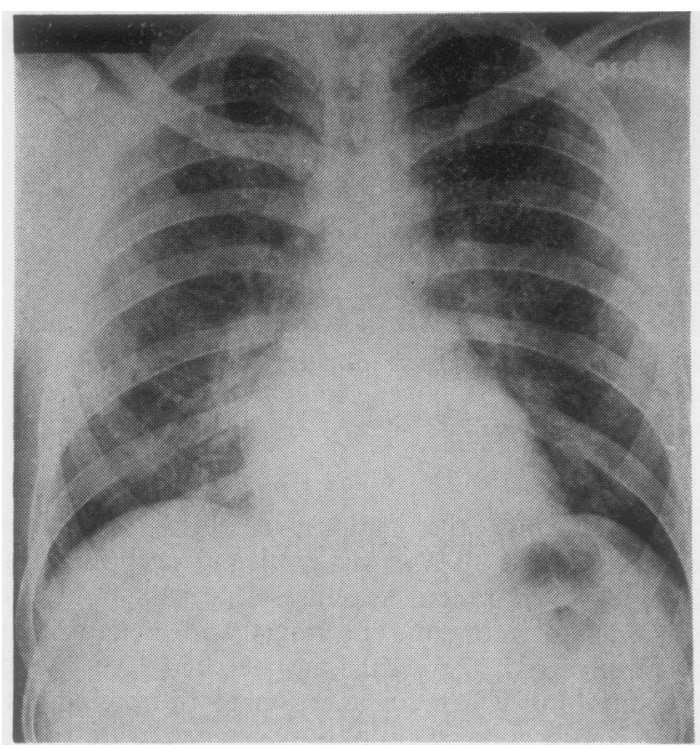

Fig 6 Chest radiograph showing bilateral widespread shadowing in case 5 three days after paraquat ingestion.

At necropsy the trachea and bronchi contained blood-stained mucus. The lungs were firm and deep purple in colour; scattered petechial haemorrhages were present in the visceral pleura. The right lung weighed $900 \mathrm{~g}$ and the left lung $820 \mathrm{~g}$. On microscopical examination the lungs showed oedema, congestion, intra-alveolar haemorrhage, and intra-alveolar hyaline membranes. Welldefined spindle-shaped fibroblasts were present, both within the alveolar walls and spaces, associ- ated with collagen formation producing a fine fibrosis as defined by van Gieson's stain and a silver impregnation technique. Foci of hyperplastic bronchiolar epithelium were seen extending into and lining adjacent alveolar spaces. The heart showed toxic myocarditis, and centrilobular hepatic necrosis was present associated with a minimal inflammatory cell response. The kidneys showed tubular necrosis as in case 4 .

\section{Discussion}

These five case histories show a variety of pul- $\stackrel{\oplus}{\dot{\omega}}$ monary complications that may ensue and that are quite distinct from the more commonly des- $\vec{\sigma}$ cribed progressive pulmonary fibrosis (Matthew et al, 1968; Toner et al, 1970; Smith and Heath, 1974; Thurlbeck and Thurlbeck, 1976). The first patients (cases 1 and 2) showed on serial examination a reduction in the gas transfer factor for carbon monoxide and in one of these (case 1) basal late inspiratory crackles and bilateral radiographic shadowing developed. In both patients these pulmonary abnormalities resolved on supportive measures alone and were associated with laboratory evidence of transient minor dysfunction of either the kidneys or the liver. It appeared likely to us that these reversible pulmonary changes could be attributed to the paraquat. In case 1 there are similarities with the case of pulmonary oedema in paraquat poisoning reported by Gardiner (1972).

In contrast, case 3, who developed predominantly unilateral pulmonary radiographic changes together with clinical evidence of pneumonia, cannot be considered as having directly paraquatdamaged lungs. The pulmonary changes were thought to result from aspiration after the administration of the Fuller's Earth or the initial gastric lavage.

These findings have some interesting implications in relation to the claims made about treatments reversing paraquat-induced lung damage. Firstly, the pulmonary complications may not in fact be directly attributable to paraquat but, $\underset{\omega}{\mathrm{N}}$ rather, may have been due to pneumonia after the $\bar{\sigma}$ treatment. Alternatively, as in our first two 0 patients, the lung changes may have been induced $\overparen{D}$ by paraquat, but then resolved on supportive $\stackrel{\oplus}{?}$ measures alone.

Patients nos 4 and 5 showed many of the typical features of severe paraquat poisoning; evidence of $\overparen{D}$ renal and hepatic damage, together with severe $\mathbb{\otimes}$ dyspnoea and bilateral pulmonary shadowing on the chest radiograph, which developed a few days after ingestion. They both died within seven days 
of ingestion. At necropsy the predominant light microscopic findings in the lungs included capillary congestion, alveolar oedema and haemorrhage, hyaline membranes, and early fibrosis in case 5 . These changes were sufficient to result in death before the development of the dense fibrosis, associated in some instances with obliteration of pulmonary architecture, reported in man 9-22 days after swallowing paraquat (Smith and Heath, 1974; Thurlbeck and Thurlbeck, 1976).

Clinically, the two patients who succumbed were distinguished from the others by the rapid onset of severe breathlessness and cough producing copious quantities of sputum, the latter presumably associated with the underlying pulmonary oedema. To judge from their individual plasma paraquat concentrations, we believe that these estimations may also aid in predicting the outcome of paraquat poisoning. This is supported by our preliminary analysis of the prognostic significance of plasma paraquat concentrations. Such determinations have become only recently available after the development by Levitt (1977) of a rapid and reproducible radioimmunoassay. There is a pronounced difference between concentrations found in fatal and non-fatal cases (see table).

Plasma paraquat concentrations in 40 patients (1977-8)

\begin{tabular}{llll}
\hline & $\begin{array}{l}\text { No of } \\
\text { patients }\end{array}$ & $\begin{array}{l}\text { Plasma paraquat } \\
\text { concentrations } \\
\text { mean }(S E M) \\
(\mu g / l)\end{array}$ & $\begin{array}{l}\text { Mean time } \\
\text { after ingestion } \\
\text { (hours) }\end{array}$ \\
\hline Fatal cases & 14 & $1263(278)$ & 8.3 \\
Non-fatal cases & 26 & $214(76)$ & 8.6 \\
\hline
\end{tabular}

We propose that in man the paraquat-induced lung damage may be dose related. When small amounts of this chemical are swallowed and the initial plasma paraquat concentrations are low, there may either be no pulmonary damage or minimal changes associated with only a reduction in gas transfer factor, as in case 2 , or with both a reduction in gas transfer factor and apparent pulmonary oedema as in case 1 . This minimal paraquat "injury" may well be reversible. With the ingestion of larger amounts of this chemical, sufficient lung damage may occur to cause death from a pronounced alveolar oedema before the development of pulmonary fibrosis, as in case 5. Probably the latter complication requires survival beyond a period of six days and occurs after intermediate amounts of paraquat have been taken. This type of poisoning appears to be rare in that most patients take either small quantities (in the form of Weedol) or very large amounts, as the liquid concentrate, usually in the form of Gramoxone.

We would like to thank Dr R Goulding for his advice in the preparation of this report and $\mathrm{Dr}$ $\mathrm{T}$ Levitt who performed the plasma paraquat determinations.

\section{References}

Cooke, N J, Flenley, C D, and Matthew, H (1973). Paraquat poisoning. Quarterly Journal of Medicine, 42, 683-692.

Cotes, J (1975). Lung function. Assessment and Application in Medicine. 3rd edn. Blackwell, Oxford.

Gardiner, A J S (1972). Pulmonary oedema in paraquat poisoning. Thorax, 27, 132-135.

Levitt, T (1977). Radio-immunoassay for paraquat. Lancet, 2, 358-359.

Matthew, H, Logan, A, Woodruff, M F A, and Heard, $B$ (1968). Paraquat poisoning-lung transplantations. British Medical Journal, 3, 759-762.

Smith, P, and Heath, D (1974). Paraquat lung: A reappraisal. Thorax, 29, 643-653.

Smith, P, and Heath, D (1975). The pathology of the lung in paraquat poisoning. Journal of Clinical Pathology, 28, suppl 9, 81-93.

Thurlbeck, W M, and Thurlbeck, S M (1976). Pulmonary effects of paraquat poisoning. Chest, 69, 276-280.

Toner, P G, Vetters, J M, Spilg, W G S, and Harland, W A (1970). Fine structure of the lung lesion in a case of paraquat poisoning. Journal of Pathology, 102, 182-185.

Vale, J A, Crome, P, Volans, G N, Widdop, B, and Goulding, R (1977). Treatment of paraquat poisoning using oral sorbents and charcoal haemoperfusion. Acta pharmacologica et toxicologica, 41, suppl II, 109-117.

Widdop, B (1976). Detection of paraquat in urine. British Medical Journal, 2, 1135.

Requests for reprints to: $\operatorname{Dr} T$ Higenbottam, Guy's Hospital, London SE1 9RT. 